\title{
Peertechz
}

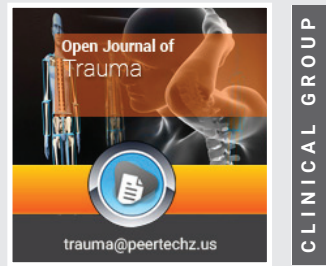

\section{Pseudoaneurism of the}

\section{brachial artery mimicking \\ a soft tissue sarcoma: Case}

\section{report}

\section{John Musubao Katsuva ${ }^{1 *}$, Simplice Kighoma Vuhaka ${ }^{1}$ and Sosthene Tsongo Vululi²}

${ }^{1}$ MMED Orthopedic Surgery, Makerere University Kampala (Muk) Healafrica Hospital, Lecturer at Goma University (UNIGOM), Goma, D.R. Congo

${ }^{2}$ Department of Radiology, Makerere University Kampala (Muk) Healafrica Hospital, Lecturer at University of Great Lakes' Countries (ULPGL), Goma, D.R. Congo
Received: 31 July, 2021

Accepted: 13 September, 2021

Published: 14 September, 2021

*Corresponding author: John Musubao Katsuva, MMED Orthopedic Surgery, Makerere University Kampala (Muk) Healafrica Hospital, Lecturer at Goma University (UNIGOM), Goma, D.R. Congo, E-mail:musubaoj@gmail.com

Keywords: Pseudo aneurism; Brachial artery; Soft tissue sarcoma; Cubital fossa

https://www.peertechzpublications.com

Check for updates

\begin{abstract}
The current case is one of the rare clinical presentations of the brachial artery pseudo aneurysm presentation in children Pseudo-aneurism is one of the late complications of a missed or untreated arterial injury. The diagnosis is suggested in the presence of clinical signs such as: an expending, ill-defined mass with or without pulsation; bruit, pain, paresthesia, or paralysis due to nerve compression. Although plain X-Rays may show a nonspecific soft tissue mass, arteriography is essential in defining differentiating pseudo aneurisms from other soft masses. We report a case of a 10years old boy with a history of a stab injury in a well vascularized left cubital fossa region. The physical examination revealed a soft tissue mass with eroded skin. Ultrasound and MRI findings were respectively of an infected soft tissue mass and probable malignant soft tissue mass. Open biopsy was planned but surgical finding revealed a pseudo aneurism of the left brachial artery before its bifurcation. Brachial arterial lesion was repaired blood flow reestablished with clinical improvement.
\end{abstract}

\section{Introduction}

In upper limbs, pseudo aneurysms around the elbow are common following blunt or penetrating trauma. They occur in neonate at a rate of about $0.05 \%$ after diagnostic catheterization and up to $1.2 \%$ after more complex procedures [1]. Clinical presentation of brachial artery pseudoaneurysms may mimic soft tissue tumors. They usually develop slowly and may take days, months or even years to develop symptoms or be detected clinically [2]. We are reporting a 10years old boy with a pseudo aneurism around the cubital fossa of the left elbow following a stab injury that was confirmed by ultrasound as a soft tissue infection and was diagnosed a soft tissue tumor on an MRI scan. The history taking and surgical removal was that of a pseudo aneurism of the left brachial artery in the cubital fossa. In a history of injury in a well vascularized zone such as a cubital fossa region, a pseudo aneurysm diagnosis should be considered.

\section{Case presentation}

A 10-year-old boy presented to our outpatient's orthopedic clinic complaining with a bleeding painful mass over the left cubital fossa. This mass started as a small swelling within a scar on the left distal arm. He reports having been stabbed eight months earlier by his younger brother while playing at home but the wound healed soon after.

Over time, five months later the swelling increased to became a huge painful mass. Therefore, He consulted traditional healers and was treated with herbs solutions and local application over the mass. Thereafter, skin erosion, worsening of the swelling, paresthesia in the hand and increased pain were motivate for medical care seeking in health centers. Eight months following a stab wound injury, the boy presented to our OPD clinic Figure 1.

Thorough physical examination revealed, an ill-defined 
margins soft mass, tender with eroded erythematous/ reddish skin. Visible dilated veins over a diffuse mass measuring $10 \times 8 \mathrm{~cm}$ over the left cubital fossa. The mass was warm without fluctuations, immobile, and variegated in consistency. There was no palpable thrill and no bruit. The elbow joint held in 110degrees flexion. Severe pain, made any passive movements impossible at the elbow joint. At the wrist joint, the radial pulsations were feeble, Tunnel's test lightly tapping (percussing) over the nerve to elicit a sensation of tingling or "pins and needles» in the distribution of the nerve produced paresthesia distally. Phalen's test (The patient is asked to hold his wrist in complete and forced flexion pushing the dorsal surfaces of both hands together for 30-60 seconds) and median nerve compression were negative. However, limb was warm with normal capillary refill time. Following the above clinical examination, a diagnosis of a post traumatic brachial artery pseudoaneurism was worked out with exclusion of soft tissue malignant tumor or infection to be investigated.

Noting that the patient presented with his radiological, ultrasound, MRI and blood investigations as presented below Figures 2,3.

A plain radiograph showing a soft tissue shadow involving the anterior aspect of the distal arm and upper fore arm in the left cubital fossa with no evidence of bone lesion or periosteal reaction signs.

Cubital fossa Ultrasound (US) examination showed per articular fluid collection suggesting an infection.

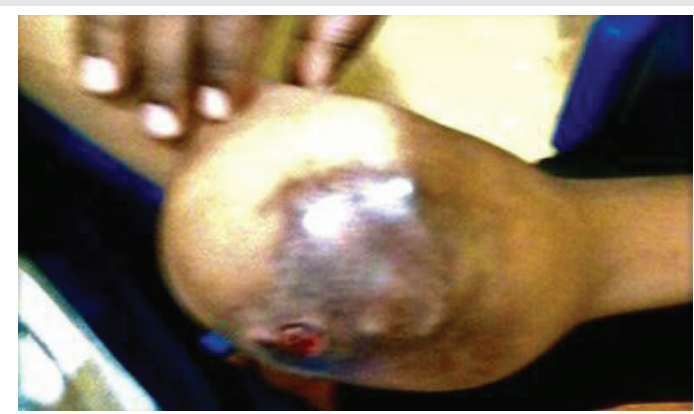

Figure 1: Left Cubital fossa mass seen at clinical presentation of a 10Years boy after 8 months after a stab wound.

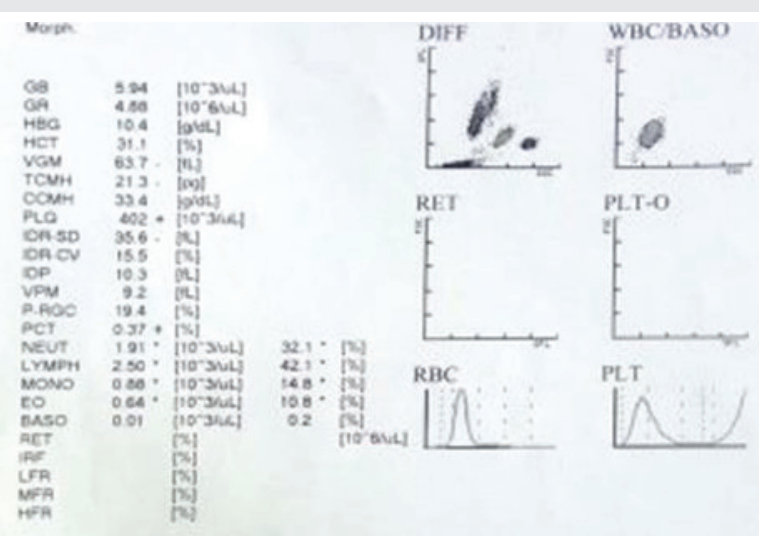

Figure 2: Laboratory Investigations showing a normal CBC exam His laboratory investigations showed hemoglobin at $10.4 \mathrm{~g} / \mathrm{dl}$, total count $5,940 / \mathrm{mm} 3$ and an elevated erythrocyte sedimentation rate (ESR).

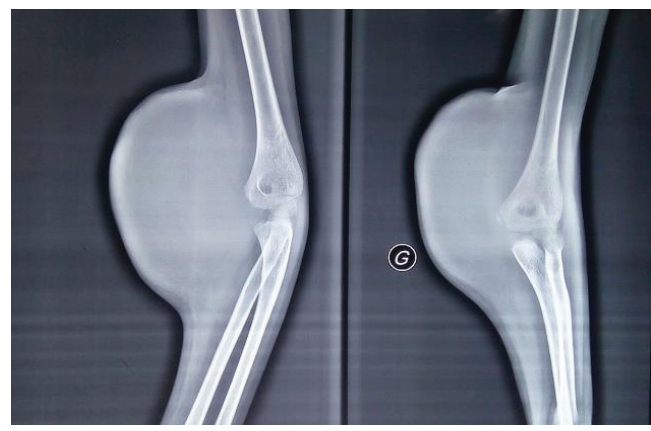

Figure 3: AP and Lateral $x$-rays left elbow normal bone density and soft tissue swelling.

A Magnetic Resonance Imaging (MRI) examination of the elbow showed a heterogeneous soft tissue ovoid hyper intense lesion measuring $105 \times 105 \times 130 \mathrm{~mm}$, involving the anterior intramuscular compartment. The lesion enclosed the neurovascular bundle with no evidence of thrombosis. The lesion was predominantly hyper intense in T2 images with multiple thick internal septations noted. T1 images were isointense with the surrounding muscle. The findings were suggestive of a soft tissue infantile fibro sarcoma (Figure 4). A contrast study was not done

Following these investigations, soft tissue infections and malignant tumor confirmed by ultrasound and MRI respectively were considered.

Conflict between clinical findings and radiological investigations brought out a dilemma in the management of the case. An open biopsy was decided under general anesthesia.

\section{Surgical procedure}

Under general anesthesia, with the patient supine on the operating table, the arm in the anatomic position and tourniquet applied on the proximal arm, Careful mass dissection showed a capsulated mass involving the brachial artery in the cubital fossa before the bifurcation into ulnar and radial artery Figures 5,6 .

The sac was excised and the opening in the brachial artery repaired. Reconstruction of damaged brachial artery warranted and restoration of a normal blood flow. The swelling appeared to have decompressed and reduced in size, and the wound was closed over a drain. The histopathological examination was consistent with an organizing hematoma. Results of microbiologic examination of the aneurysmal capsule were negative for microorganisms. Post-operatively, the hand was well perfused and the elbow deformity improved with physiotherapy.

\section{Discussion}

A pseudoaneurysm occurs after a disruption in arterial wall continuity, with blood dissecting into surrounding soft tissues without an arterial wall incorporated in the aneurismal sac [3]. The causes of a pseudo aneurysm include iatrogenic, traumatic, neoplastic, infective, vasculitis, and inflammatory etiology. Traumatic pseudoaneurysms are more common around the knee and elbow They can occur following blunt 


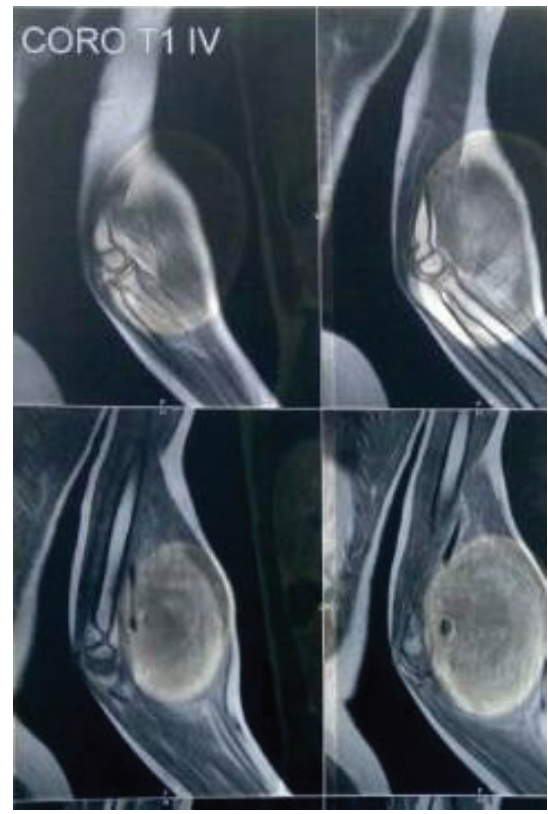

Figure 4: MRI Scan Left elbow.

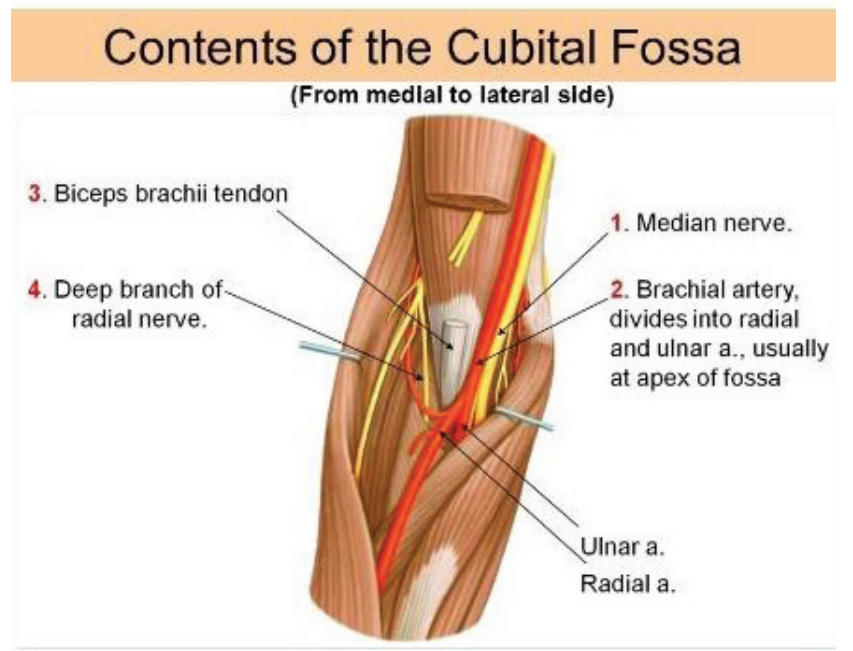

Figure 5: Ultrasound of the below show an intra and periarticular fluid collection.

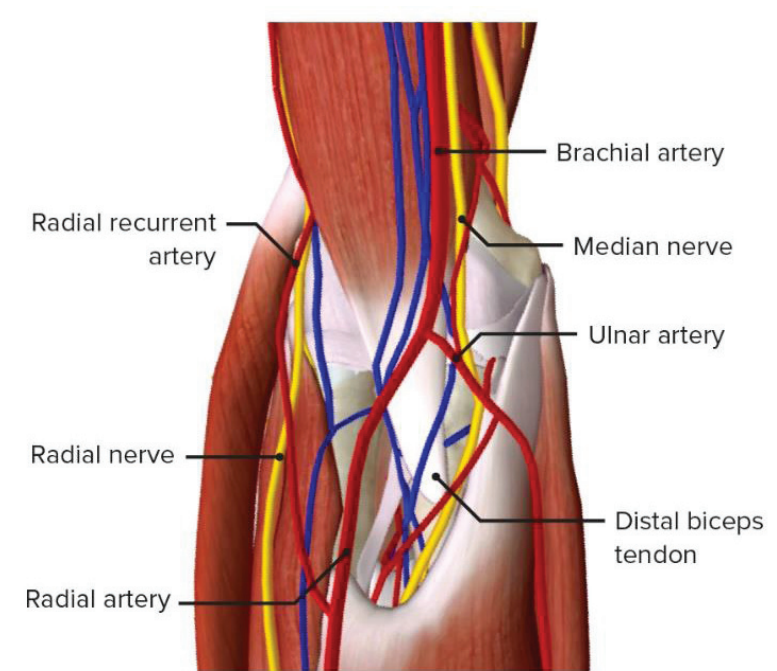

Figure 6:A capsulated mass involving the brachial artery in the cubital fossa before the bifurcation into ulnar and radial artery. or penetrating trauma [4]. We are presenting a 10years old male who sustained traumatic pseudoaneurysm following a stab wound. Studies have reported that, the mean period from injury to hospital admission may vary from less than one week to years $[5,6]$. In the current report, the period from injury to the hospital admission was eight months. The literature suggest that pseudoaneurysms due to penetrating or blunt trauma are seen in patients of every age and at any location [7]. Similar to other studies, the patient presented with signs of long-standing pseudoaneurysms essentially hemorrhagic swelling with skin erosion and neurological compression [810]. Despite this clinical picture mimicking an aggressive soft tissue tumor the patient presented any evidence of metastasis at presentation.

The initial imaging modality of choice in a pseudoaneurysm is a duplex ultrasound. A computed angiography remains the gold standard [3]. However, in this report duplex ultrasound was not requested for because we did not suspect pseudoaneurysm. Plain radiographs in this patient did not reveal any bony erosions or scalloping apart from a large soft tissue component. Our patients' imaging was in line with an aggressive soft tissue tumor and pseudoaneurysm was not considered in the diagnosis.

Some pseudoaneurysms may simply be observed if they are less than $10 \mathrm{~mm}$ in size, are asymptomatic, and involve arteries of minor importance. Larger aneurysms, those that become symptomatic, or those that involve major arteries in which occlusion would threaten severe ischemic effects generally require intervention. Multiple management strategies can be applied to pseudoaneurysms; options range from ultrasound compression 13,14 to thrombin injection, 15 radiologic intervention and surgery [11-13].

\section{Conclusion}

The current case is one of the rare clinical presentations of the brachial artery pseudo aneurysm presentation in children.

Delay in diagnosing traumatic pseudoaneurysms can mimic softs tissue malignancy tumor or infection (abscess) as presented in the current case. Dilemma in the choosing between open biopsy taking and radiology investigations will might be avoided by having a throughout patient history taking, physical examination and doppler evaluation. These steps are mandatory for a successful management of post traumatic pseudoaneurysms.

In the present case report, open biopsy was planned but surgical finding revealed a pseudo aneurism of the left brachial artery before its bifurcation into radial and ulna arteries.

Brachial arterial lesion was repaired blood flow reestablished. The patient clinical outcome was perfect.

\section{References}

1. Landau D, Schreiber R, Szendro G, Golcman L (2003) Brachial artery pseudoaneurysm in a premature infant. Arch Dis Child Fetal Neonatal Ed 88 F152-F153. Link: https://bit.ly/3zbQAWN

Citation: Katsuva JM, Vuhaka SK, Vululi ST (2021) Pseudoaneurism of the brachial artery mimicking a soft tissue sarcoma: Case report. Open J Trauma 5(1): 006- 
2. Mudoni A, Cornacchiari M, Gallieni M, Guastoni C, McGrogan D, et al. (2015) Aneurysms and pseudoaneurysms in dialysis access. Clin Kidney $\mathrm{J}$ 8: 363367. Link: https://bit.ly/3zacTv0

3. Sueyoshi E, Sakamoto I, Nakashima K, Minami K, Hayashi K (2005) Visceral and peripheral arterial pseudoaneurysms. AJR Am J Roentgenol 185: 741749. Link: https://bit.ly/3Co95cL

4. Erler K, Ozdemir MT, Oguz E, Basbozkurt M (2004) Does false aneurysm behave like a sarcoma? Distal femoral arterial false aneurysm simulated a malign mesenchymal tumor. Arch Orthop Trauma Surg 124: 60-63. Link: https://bit.ly/3AdrOlq

5. Yetkin U, Gurbuz A (2003) Post-traumatic pseudoaneurysm of the brachial artery and its surgical treatment. Tex Heart Inst J 30: 293-297. Link: https://bit.ly/3z6LMBR

6. Laohapoonrungsee A, Sirirungruangsarn Y, Arpornchayanon O (2005) Pseudoaneurysm of profunda femoris artery following internal fixation of intertrochanteric fracture: two cases report. J Med Assoc Thai 88: 1703-1706. Link: https://bit.ly/3k64lg0

7. Kuivaniemi H, Shibamura H, Arthur C, Berguer R, Cole CW, et al. (2003) Familial abdominal aortic aneurysms: collection of 233 multiplex families. J Vasc Surg 37: 340-345. Link: https://bit.ly/3cf2q4x
8. Ghazi MA, Khan AM, Akram Y, Cheema MA (2006) Brachial artery aneurysm Japan Medical Association Journal 49: 173-175. Link: https://bit.ly/3nvVThu

9. Gantz E, Sweet M, Jakim I (1988) False aneurysm mimicking an aggressive soft-tissue tumor. A case report. J Bone Joint Surg Am 70: 1090-1092. Link: https://bit.ly/3k9uMqx

10. Tetik O, Yilik L, Besir Y, Can A, Ozbek C, et al. (2005) Surgical treatment of axillary artery aneurysm. Tex Heart Inst $\mathrm{J}$ 32: 186-188. Link: https://bit.ly/3tCf1vr

11. Paschalidis M, Theiss W, Kölling K, Busch R, Schömig A (2006) Randomised comparison of manual compression repair versus ultrasound guided compression repair of postcatheterisation femoral pseudoaneurysms. Heart 92: 251-252. Link: https://bit.ly/2YTMqGG

12. Danzi GB, Sesana M, Capuano C, Baglini R, Bellosta R, et al. (2005) Compression repair versus low-dose thrombin injection for the treatment of iatrogenic femoral pseudoaneurysm: a retrospective case-control study. Ital Heart J 6: 384-389. Link: https://bit.ly/391JAkN

13. NOlsen DM, Rodriguez JA, Vranic M, Ramaiah V, Ravi R, et al. (2002) A prospective study of ultrasound scan-guided thrombin injection of femoral pseudoaneurysm: a trend toward minimal medication. J Vasc Surg 36: 779782. Link: https://bit.ly/3tCll6d

\section{Discover a bigger Impact and Visibility of your article publication with}

\section{Peertechz Publications}

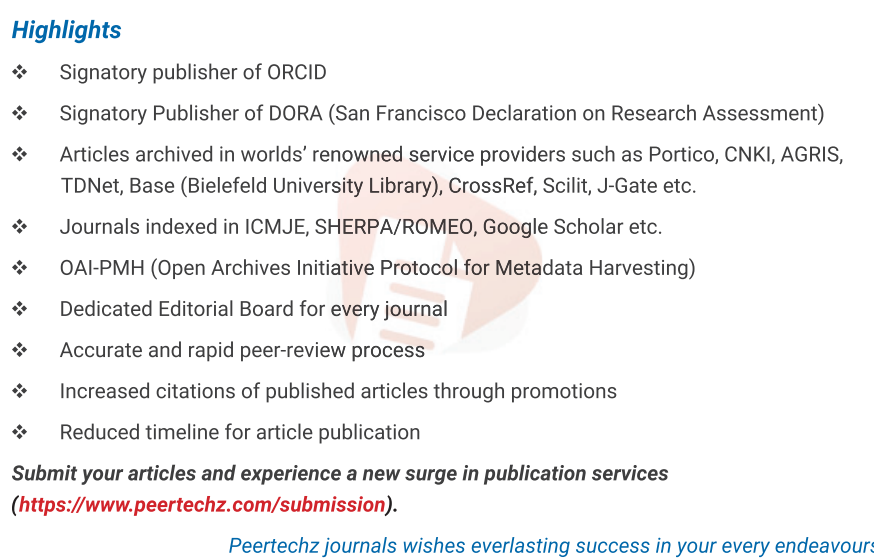

Copyright: (C) 2021 Katsuva JM, et al. This is an open-access article distributed under the terms of the Creative Commons Attribution License, which permits unrestricted use, distribution, and reproduction in any medium, provided the original author and source are credited.

Citation: Katsuva JM, Vuhaka SK, Vululi ST (2021) Pseudoaneurism of the brachial artery mimicking a soft tissue sarcoma: Case report. Open J Trauma 5(1): 006009. DOI: https://dx.doi.org/10.17352/ojt.000036 